Methods: APR treatment outcomes were evaluated in a subset of pts with baseline (BL) BASDAI $\geq 4$ ("subset") over 156 wks.

Results: BL BASDAI $\geq 4$ was reported for $454 / 1493(30 \%)$ pts. Mean PsA duration was similar between the subset and rest of the PALACE 1-3 population $(n=1039)$; mean BL psoriasis body surface area (BSA) and percentage of pts with $\mathrm{BSA} \geq 3 \%$ were slightly higher. The subset had higher mean BL values vs the rest of PALACE $1-3$ pts for C-reactive protein (1.12 vs 0.93 ), pain VAS (63.6 vs $53.8 \mathrm{~mm}$ ), pt's global assessment of disease activity (62.2 vs $53.5 \mathrm{~mm}$ ), and physician's global assessment of disease activity (PhGA; 59.0 vs $53.0 \mathrm{~mm}$ ) and markedly worse mean HAQ-DI (1.41 vs 1.08), SF-36v2 Physical Functioning (30.6 vs 35.8$)$, and FACIT-F (25.7 vs 31.8$)$ scores. Despite disease activity differences, BL concomitant oral DMARDs were similar in both groups: 1 DMARD in $61.0 \%$ (subset) vs $57.8 \%$ (rest of PALACE 1-3 pts); methotrexate was the most common DMARD. In the subset, $73.6 \%$ had been treated with only oral DMARDs prestudy (44.9\% with only 1 ); $25.1 \%$ had prior biologic use. Mean BL BASDAI in the subset was 6.6 with APR and 6.4 with placebo (PBO). Mean BL BASDAl question 2 score, referring directly to spinal and hip pain, was 6.7. APR resulted in greater mean improvement in BASDAI vs PBO at Wk $16(-1.53$ vs $-0.91 ; P=0.0173)$ and Wk 24 (Table). As early as Wk 16, a 19\% mean decrease in the question 2 score was seen with APR vs an increase with PBO. Other disease measures significantly improved early in treatment, including HAQ-DI, fatigue, PhGA, and mPsARC (Table). Long-term improvement was seen across measures, with mean BASDAI reductions of 2.18 at Wk 52 and 2.19 at Wk 156 (Table) and question 2 reductions of 1.94 and 2.28 , respectively; treatment resulted in a shift toward lower BASDAI across the subset, with a significant proportion reaching BASDAI $<4$.

\begin{tabular}{|c|c|c|c|c|}
\hline \multicolumn{5}{|c|}{ Outcomes at Wk 24, Wk 52, and Wk 156 in Pts With BASDAI $\geq 4$ at BL } \\
\hline & \multicolumn{2}{|c|}{ Wk 24} & Wk 52 & Wk 156 \\
\hline & $\begin{array}{c}\text { APR } \\
n=156\end{array}$ & $\begin{array}{l}\mathrm{PBO} \\
\mathrm{n}=151\end{array}$ & $\begin{array}{c}\text { APR } \\
n=125\end{array}$ & $\begin{array}{c}\text { APR } \\
n=127\end{array}$ \\
\hline BASDAl, mean BL & 6.6 & 6.4 & 6.6 & 6.6 \\
\hline BASDAl, mean change from $B L$ & $-1.64^{*}$ & -0.74 & -2.18 & -2.19 \\
\hline Swollen joint count, mean change & $-5.5^{*}$ & -2.4 & -8.5 & -10.6 \\
\hline HAQ-DI, mean change & $-0.301^{x}$ & -0.117 & -0.464 & -0.448 \\
\hline SF-36v2 PF, mean change & $4.98^{*}$ & 1.76 & 7.06 & 8.21 \\
\hline Pain VAS, mean change, $\mathrm{mm}$ & $-12.6^{*}$ & -7.9 & -22.1 & -21.9 \\
\hline FACIT-F, mean change & $4.38^{*}$ & 1.29 & 6.77 & 6.31 \\
\hline $\begin{array}{l}\text { Pt's global assessment of disease } \\
\text { activity, mean change (VAS mm) }\end{array}$ & -10.9 & -5.7 & -19.8 & -21.2 \\
\hline PhGA, mean change (VAS mm) & $-22.1^{1}$ & -7.4 & -34.3 & -40.2 \\
\hline Proportion meeting mPsARC, $\%$ & $46.2^{s}$ & 23.8 & 77.9 & 84.1 \\
\hline
\end{tabular}

The $n$ may vary slightly for the end points at pts randomized at BL in the subset; last-observation-carried-forward methodology and non-respond imputation rule were applied to pts who early escaped at Wk 16 or had missing value at Wk 24 for
continuous data and binary response, respectively. For Wk 52 , the $n$ represents the number of pts continuous data and binary response, respectively. For $W k 52$, the $n$ represents the number of $p$
randomized to APR at BL in the subset, with an outcome measure at Wk 52 . For Wk 156 , the $n$ represents the number of pts who were randomized to APR (at BL. Wk 16, or Wk 24), with an outcom measure at Wk 156

${ }^{*} P<0.05 ; \$ P<0.0001$ vs $P B O$, based on an analysis of covariance model for the change from $B L$, with treatment group, BL DMARD use (yes/no), and study as factors and BL value as the covariate, and the Cochran-Mantel-Haenszel test for binary response, adjusting for BL DMARD use and study. Pt's global assessment of disease activity APR $30 \mathrm{mg}$ BID vs $P B O$ at Wk 24: $P=0.0590$.

BASDAl=Bath Ankylosing Spondylitis Disease Activity Index score; APR=apremilast $30 \mathrm{mg}$ BID $\mathrm{PBO}=$ placebo; $\mathrm{BL}=$ baseline; $\mathrm{HAQ}-\mathrm{DI}=$ Health Assessment Questionnaire-Disability Index score; SF-36v2 $\mathrm{PF}=36$-item Short-Form Health Survey version 2 Physical Functioning domain score; VAS=visual analog scale; FACIT-F=Functional Assessment of Chronic Illness Therapy-Fatigue score; PhGA=physician's global assessment of disease activity; mPsARC=modified Psoriatic Arthritis Response Criteria; DMARD=disease-modifying anti-rheumatic drug.

Conclusions: In this post hoc analysis of pooled data, pts reporting BASDAI $\geq 4$ at $\mathrm{BL}$ appear to experience greater disease burden, including disability, pain, and fatigue; effective treatment strategies may not have been available. APR treatment resulted in long-term improvements in BASDAI and other measures in pts with clinically suspected axial disease.

Disclosure of Interest: P. Mease Grant/research support from: Abbott, Amgen, Biogen Idec, BMS, Celgene Corporation, Genentech, Janssen, Eli Lilly, Novartis, Pfizer, Roche, UCB, Consultant for: Abbott, Amgen, Biogen Idec, BMS, Celgene Corporation, Genentech, Janssen, Eli Lilly, Novartis, Pfizer, Roche, UCB, Speakers bureau: Abbott, Amgen, Biogen Idec, BMS, Genentech, Janssen, Eli Lilly, Pfizer, UCB, H. Marzo-Ortega: None declared, A. Poder: None declared, F. Van den Bosch Consultant for: AbbVie, Celgene Corporation, Merck, Pfizer, UCB, Janssen, J. Wollenhaupt Grant/research support from: Abbott, BMS, MSD, Pfizer, UCB, Consultant for: Abbott, BMS, MSD, Pfizer, UCB, E. Lespessailles Grant/research support from: Amgen, Eli Lilly, Novartis, Servier, Speakers bureau: Amgen, Eli Lilly, Novartis, Servier, M. Mcllraith Employee of: Celgene Corporation, L. Teng Employee of: Celgene Corporation, S. Hall Consultant for: Boehringer Ingelheim, MSD, Roche, Schering-Plough, Servier, Wyeth, Paid instructor for: Amgen, AstraZeneca, Boehringer Ingelheim, Centocor, GSK, MSD, Pfizer, Sanofi Aventis, Sanofi Pasteur, Schering-Plough, Serono, Wyeth, Speakers bureau: Boehringer Ingelheim, GSK, MSD, Pfizer, Roche, Sanofi Aventis, Schering-Plough, Wyeth DOI: 10.1136/annrheumdis-2017-eular.3299

\section{FRI0513 LONG-TERM (156 WEEKS) IMPROVEMENTS IN PHYSICAL FUNCTION OF DMARD-NAÏVE AND DMARD/BIOLOGIC-EXPERIENCED PSORIATIC ARTHRITIS PATIENTS TREATED WITH APREMILAST: DATA FROM A LARGE DATABASE OF 4 PHASE III CLINICAL TRIALS}

P.J. Mease $^{1}$, A. Wells ${ }^{2}$, J. Wollenhaupt ${ }^{3}$, S. Hall ${ }^{4}$, F. Van den Bosch ${ }^{5}$, E. Lespessailles ${ }^{6}$, M. Mcllraith ${ }^{7}$, D. Nguyen ${ }^{7}$, L. Teng ${ }^{7}$, C.J. Edwards ${ }^{8}$. ${ }^{1}$ Swedish Medical Center and University of Washington School of Medicine, Seattle; ${ }^{2}$ Rheumatology and Immunotherapy Center, Franklin, United States; ${ }^{3}$ Schön Klinik Hamburg Eilbek, Hamburg, Germany; ${ }^{4}$ Monash University, CabriniHealth, Melbourne, Australia; ${ }^{5}$ UZ Gent, Gent, Belgium; ${ }^{6}$ University of Orléans, Orléans, France, ${ }^{7}$ Celgene Corporation, Summit, United States;

${ }^{8}$ University Hospital Southampton, Southampton, United Kingdom

Background: Improving and preserving patient (pt) physical function is an important goal for psoriatic arthritis (PsA)

Objectives: To evaluate apremilast's (APR) effects on physical function/functional status for up to $3 \mathrm{yrs}$ in DMARD/biologic-experienced (PALACE 1-3 [PAL1-3] pooled data) and DMARD-naive (PALACE 4 [PAL4]) pts with active PsA.

Methods: Pts were randomized (1:1:1) to placebo (PBO), APR $30 \mathrm{mg}$ BID (APR30), or $20 \mathrm{mg}$ BID (APR20) at baseline (BL). The primary endpoint was at Wk16; a long-term extension is ongoing. A detailed study design has been previously presented. Assessed were mean change from BL HAQ-DI scores and proportions of pts reaching HAQ-DI MCID and reaching scores $<1.0$ (below clinically significant disability), $\leq 0.5$ (minimal disability), and $\leq 0.25$ (general population). Wk16 data were analyzed by LOCF. Wk156 data are as observed. Mean change and MCID outcomes are for all pts receiving APR30 at any time during the study; disability level data are for pts randomized to APR30 at BL. Results: PAL1-3 (biologic/DMARD-experienced) and PAL4 (DMARD-naïve) pts had similar BL SJC/TJC and DAS-28 (CRP), indicating active PSA. PAL1-3 pts had longer mean duration of PSA and psoriasis, higher PASI scores, and greater corticosteroid use at BL. Despite differences, BL physical disability was clinically significant in both populations (mean HAQ-DI, PAL1-3: 1.2; PAL4: 1.1). Marked disability at $B L$ was seen in some pts randomized to APR30, with HAQ-DI scores up to 2.63-2.88. More PAL1-3 vs PAL4 APR30 pts had BL HAQ-DI >1.0 (60\% vs $54 \%$ ), >1.5 (marked difficulty/need for assistive devices, $31 \%$ vs $21 \%$ ), and $>1.75$ (major disability, $19 \%$ vs $10 \%$ ), highlighting need for early, effective treatment (tx). Few APR30 pts had BL scores $\leq 0.5$ (18-22\%) or $\leq 0.25(10-14 \%)$. At Wk16, physical function significantly improved with APR30 vs PBO (mean HAQ-DI change, PAL1-3: -0.23 vs -0.08 ; PAL4: -0.21 vs 0.03 ; both $P<0.0001$ ) and more APR30 vs PBO pts reached HAQ-DI MCID $>0.30$ and $>0.35$. As early as Wk16, overall disability levels also shifted; more APR30 vs PBO pts achieved HAQ-DI $\leq 1.0$ (PAL1-3: $56 \%$ vs $48 \%$; PAL4: $60 \%$ vs $52 \%$ ). At Wk156, marked achievement of HAQ-DI $\leq 1.0, \leq 0.5$, and $\leq 0.25$ was observed in both populations (Table). LOCF analyses confirmed Wk156 results.

\begin{tabular}{|c|c|c|}
\hline \multicolumn{3}{|c|}{ Pts Achieving Improvement in Physical Function by HAQ-DI Level at Wk156* } \\
\hline \multirow[b]{2}{*}{$\begin{array}{l}\text { Pts Achieving HAQ-DI Disability } \\
\text { Threshold, \% }\end{array}$} & PAL1-3 & PAL4 \\
\hline & $\begin{array}{l}\text { APR30 } \\
n=279 \S\end{array}$ & $\begin{array}{l}\text { APR30 } \\
n=94^{\S}\end{array}$ \\
\hline$\leq 1.0^{1}$ & 62 & 65 \\
\hline$\leq 0.5^{2}$ & 38 & 45 \\
\hline$\leq 0.25$ & 28 & 42 \\
\hline Pts Achieving HAQ-DI MCID Levels, \% & $\begin{array}{l}\text { APR30 } \\
n=413^{\ddagger}\end{array}$ & $\begin{array}{l}\text { APR30 } \\
n=143^{\ddagger}\end{array}$ \\
\hline$\geq 0.30^{31}$ & 48 & 48 \\
\hline$\geq 0.35^{4 \pi}$ & 48 & 48 \\
\hline \multicolumn{3}{|c|}{ 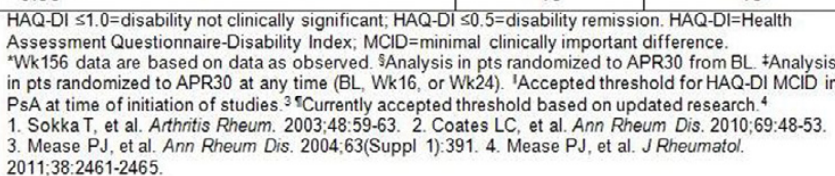 } \\
\hline
\end{tabular}

Conclusions: With APR30 tx, physical disability improved early; functionality was maintained for up to 3 yrs. Most pts achieved HAQ-DI $\leq 1.0$; many attained minimal/mild physical impairment. Over $40 \%$ of pts receiving APR30 earlier in the tx paradigm had functional ability similar to population norms after 3 yrs; shorter disease duration and no prior DMARD/biologics use in this population suggests that earlier APR tx may increase the likelihood of maximal functionality for some pts.

Disclosure of Interest: P. Mease Grant/research support from: Abbott, Amgen, Biogen Idec, BMS, Celgene Corporation, Genentech, Janssen, Eli Lilly, Novartis, Pfizer, Roche, UCB, Consultant for: Abbott, Amgen, Biogen Idec, BMS, Celgene Corporation, Genentech, Janssen, Eli Lilly, Novartis, Pfizer, Roche, UCB, Speakers bureau: Abbott, Amgen, Biogen Idec, BMS, Genentech, Janssen, Eli Lilly, Pfizer, UCB, A. Wells Grant/research support from: Celgene Corporation, J. Wollenhaupt Grant/research support from: Abbott, BMS, MSD, Pfizer, UCB, Consultant for: Abbott, BMS, MSD, Pfizer, UCB, S. Hall Consultant for: Boehringer Ingelheim, MSD, Roche, Schering-Plough, Servier, Wyeth, Paid instructor for: Amgen, AstraZeneca, Boehringer Ingelheim, Centocor, GSK, MSD, Pfizer, Sanofi Aventis, Sanofi Pasteur, Schering-Plough, Serono, Wyeth, Speakers bureau: Boehringer Ingelheim, GSK, MSD, Pfizer, Roche, Sanofi Aventis, Schering-Plough, Wyeth, 
F. Van den Bosch Consultant for: AbbVie, Celgene Corporation, Merck, Pfizer, UCB, Janssen, E. Lespessailles Grant/research support from: Amgen, Eli Lilly, Novartis, Servier, Speakers bureau: Amgen, Eli Lilly, Novartis, Servier, M. Mcllraith Employee of: Celgene Corporation, D. Nguyen Employee of: Celgene Corporation, L. Teng Employee of: Celgene Corporation, C. Edwards Grant/research support from: Celgene Corporation, Pfizer, Roche, Samsung, Consultant for: Celgene Corporation, Pfizer, Roche, Samsung, Speakers bureau: Abbott, GSK, Pfizer, Roche

DOI: 10.1136/annrheumdis-2017-eular.3019

\section{FRI0514 PSORIATIC ARTHRITIS IS ASSOCIATED WITH DIAGNOSTIC DELAY AND WORSE OUTCOME AT THREE MONTHS WHEN COMPARED TO RHEUMATOID ARTHRITIS: RESULTS FROM THE UK NATIONAL AUDIT FOR INFLAMMATORY ARTHRITIS}

R. Holland ${ }^{1}$, A. Davis ${ }^{2}$, A. Green ${ }^{2}$, A. Nightingale ${ }^{2}$, R. Charlton ${ }^{2}$, E. Cullen ${ }^{3}$ N. McHugh ${ }^{1}$. 'Royal National Hospital for Rheumatic Diseases; ${ }^{2}$ University of Bath, Bath; ${ }^{3}$ Celgene Ltd, London, United Kingdom

Background: Psoriatic arthritis (PsA) is underdiagnosed in primary care, and can be difficult to distinguish from osteoarthritis. Accumulating evidence suggests that diagnostic delay is associated with poorer functional outcome despite treatment. Objectives: To develop a better understanding of the diagnostic delay and burden of disease in patients with PsA, and to investigate management within the first three months of diagnosis.

Methods: Data were analysed on all participants with a final diagnosis of PsA from The National Clinical Audit for Rheumatoid and Early Inflammatory Arthritis, undertaken by the British Society for Rheumatology and commissioned by the Healthcare Quality Improvement Programme, recruited between 1/2/2014 and 30/10/2015. Data were collected from patients and clinicians at baseline and three months. 1016 participants with PsA (mean age $49.4 \pm 14.5$ years; $54 \%$ female) were matched $1: 1$ by age and sex with participants with Rheumatoid Arthritis (RA).

Results: Patients with PsA had a significantly longer delay to presentation and diagnosis than those with RA $(p<0.02$, Table 1$)$, and this remained significant when adjusted for age, sex, ethnicity and social status.

PsA patients had lower median tender (4.0 vs 7.0 ) and swollen (3.0 vs 5.0 ) joint counts and lower mean baseline ESR (21.9 vs $27.8 \mathrm{~mm} / \mathrm{hr}$ ) and CRP (16.2 vs $24.2 \mathrm{mg} / \mathrm{L})$ values than patients with $R A$ ( $p<0.01$ for all comparisons), and this remained significant when adjusted for potential confounders. Mean baseline scores for the Inflammatory Arthritis Impact of Disease (IAID) questionnaire were lower in patients with PsA $(5.34 \pm 2.25$ vs $5.94 \pm 2.35$ in RA, lower scores indicating less impact), although this was not statistically significant when adjusted for demographics and disease activity $(p=0.36)$. There was no significant difference between physical function at baseline between the groups (median HAQ 0.88 PsA vs $1.13 \mathrm{RA}, \mathrm{p}=0.70)$.

At follow-up, patients with PsA had significantly higher mean IAID scores $(4.32 \pm 2.60$ vs $3.78 \pm 2.56, P<0.05)$. In those with paired results, the mean improvement in IAID score was $1.32(95 \% \mathrm{Cl} 0.99-1.65)$ in PsA vs $2.37(95 \% \mathrm{Cl}$ 2.07-2.67) in RA. In patients with high disease activity at baseline (DAS28 > 5.1) a good EULAR response was seen in only $21.4 \%$ in PsA vs $30.3 \%$ in RA. There was a marked difference in the DMARDs initially prescribed, and the differences

Table 1. Median delay in weeks

\begin{tabular}{lccccc}
\hline & \multicolumn{2}{c}{ PsA } & & \multicolumn{2}{c}{ RA } \\
\cline { 2 - 3 } \cline { 5 - 6 } & Unadjusted & Adjusted $^{\star}$ & & Unadjusted & Adjusted $^{*}$ \\
\hline Symptoms to GP Presentation & 8.9 & 8.9 & & 7.1 & 6.6 \\
GP Presentation to Referral & 5.3 & 5.4 & & 4.3 & 4 \\
GP Presentation to Diagnosis & 12.4 & 12.1 & & 9.9 & 9.7 \\
Symptoms to Diagnosis & 29.0 & 28.6 & & 21.4 & 21.6 \\
\hline
\end{tabular}

${ }^{*}$ Adjusted for age, sex, ethnicity and deprivation Index; $p<0.02$ for all between group comparisons.
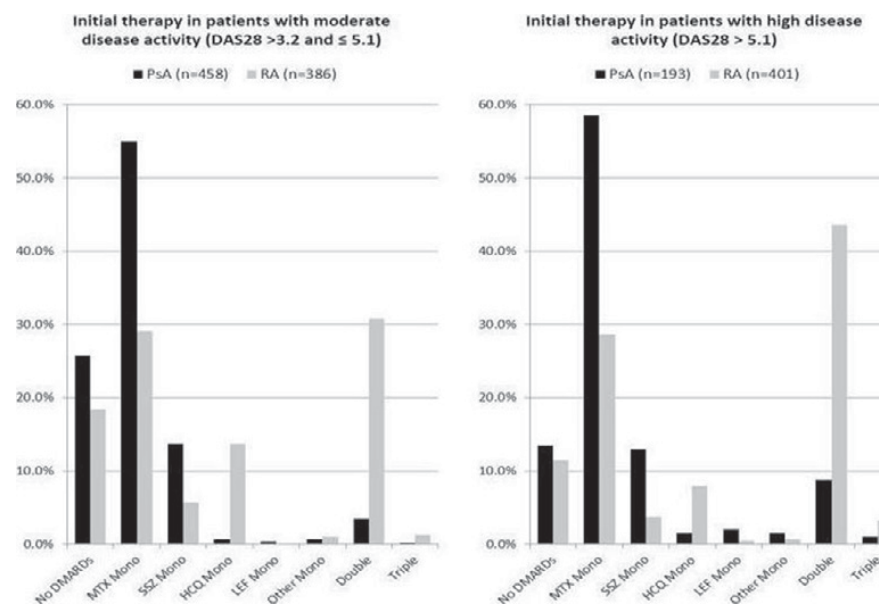

remained significant when only those with a DAS28 score indicating moderate or high disease activity at presentation were analysed, as shown in Figure 1.

Conclusions: This study demonstrates that patients with PsA have a longer delay to diagnosis between both symptom onset and presentation to primary care, and referral to secondary care and diagnosis than those with RA. Despite similar disease impact and physical function at diagnosis, patients with PsA are less likely to receive combination DMARD treatment, and have increased disease burden at three months.

Disclosure of Interest: None declared

DOI: 10.1136/annrheumdis-2017-eular.5066

\section{FRI0515 CLASSIC CARDIOVASCULAR RISK FACTORS AND MINIMAL DISEASE ACTIVITY IN PSORIATIC ARTHRITIS: RESULTS OF A SPANISH MULTICENTER STUDY}

$\underline{\text { R. Queiro }}^{1}$, J.D. Cañete ${ }^{2}$, C. Montilla ${ }^{3}$, M.A. Abad $^{3}$, M. Montoro ${ }^{3}$, S. Gómez $^{3}$, A. Cábez $^{3}$, J.C. Torre Alonso ${ }^{3}$, J.A. Román Ivorra ${ }^{3}$, J. Sanz $^{3}$, J. Salvatierra $^{3}$, J. Calvo Alén ${ }^{3}$, A. Sellas ${ }^{3}$, F.J. Rodriguez ${ }^{3}$, A. Bermúdez $^{3}$, M. Romero $^{3}$, M. Riesco ${ }^{3}$, J.C. Cobeta $^{3}$, F. Medina ${ }^{3}$, A. Aragón ${ }^{3}$, M.L. García ${ }^{3}$

A. Urruticoechea ${ }^{3} .{ }^{1}$ Rheumatology, Hospital Universitario Central de Asturias, Oviedo; ${ }^{2}$ Rheumatology, HU, Clinic and IDIBAPS, Barcelona, Spain; ${ }^{3}$ Affiliation not provided

Background: Some cardiovascular risk factors (CVRF) have been related to poorer responses to biological therapy ${ }^{1}$. We aimed to evaluate the potential link between the MDA response and the presence of CVRF in patients treated with traditional and/or biological DMARDs.

Objectives: The objective has been to evaluate the potential association between classic CVRF and the probability of reaching an MDA response in PsA patients.

Methods: Cross-sectional study carried out at 25 rheumatology outpatient clinics in patients who fulfilled the Classification for Psoriatic Arthritis (CASPAR) criteria with at least one year disease duration, and treated with biological or conventional synthetic (cs) DMARDs according to routine clinical practice in Spain. Patients were considered in MDA if they met at least $5 / 7$ of the MDA criteria ${ }^{2}$. The relationship between MDA and CVRF was evaluated by uni and multivariate analyses.

Results: 227 patients were included, 133 (58.6\%) were in MDA state (52\% on anti-TNF $\alpha$ monotherapy, $24 \%$ on csDMARD monotherapy, $24 \%$ on anti-TNF $\alpha$ in combination with csDMARD). Among the classic CVRF, tobacco (crude OR: 0.54), sedentary lifestyle (crude OR: 1.95), hyperuricemia (crude OR: 2.01) and obesity (crude OR: 1.54) were related to the likelihood of MDA in the univariate model $(p<0.25)$. The only CVRF related to the MDA response in the multivariate analysis was a sedentary lifestyle (OR $3.13,95 \% \mathrm{Cl}: 1.50-6.53 ; \mathrm{p}=0.002$ ). We did not find any association between the number of CVRF and the MDA response.

Conclusions: Contrary to what has been found in other studies, in this crosssectional multicenter study we could not find any relationship between traditional CVRF (except for sedentary lifestyle) and MDA. In any case, patients with psoriatic disease should be encouraged to maintain healthy lifestyle habits.

References:

[1] Ogdie A, Eder L. Improving cardiovascular health and metabolic comorbidities in patients with psoriatic arthritis. Int J Clin Rheumatol 2015; 10(6):451-459.

[2] Coates LC, Fransen J, Helliwell PS. Defining minimal disease activity in psoriatic arthritis: a proposed objective target for treatment. Ann Rheum Dis 2010; 69(1):48-53.

Acknowledgements: This study was funded by Pfizer.

Disclosure of Interest: None declared

DOI: 10.1136/annrheumdis-2017-eular.4083

\section{FRI0516 ASSESSMENT OF DISEASE REMISSION BY POWER DOPPLER ULTRASONOGRAPHY IN PATIENTS WITH PSORIATIC ARTHRITIS}

S. Monov ${ }^{1}$, R. Shumnalieva ${ }^{1}$, D. Monova ${ }^{2}$, A. Kopchev ${ }^{1} .{ }^{1}$ Department of Internal Medicine, Clinic of rheumatology, Medical University - Sofia; ${ }^{2}$ Medical Institute-MVR, Medical University-Sofia, Sofia, Bulgaria

Background: Treatment strategies nowadays are targeting clinical remission or low disease activity. In some patients with psoriatic arthritis (PsA) clinical findings defer from the ultrasonographic evidence of inflammation which raise the need for revising the remission criteria in the clinical practice.

Objectives: The aim of our study was to estimate the presence of subclinical synovitis by power Doppler ultrasonography (PDUS) in PSA patients, who were considered as being in clinical remission defined by DAS28-ESR (Disease activity score of 28 joints - erythrocyte sedimentation rate) for at least 6 months during the treatment course.

Methods: 64 PsA patients in clinical remission based on DAS28 - ESR $<2.6$ were included in the study. The patients were examined by two independent rheumatologists. The affected joints were assessed by PDUS (MyLab 60, Esaote) for the presence of synovial hypertrophy $(\mathrm{SH})$ and synovitis scored from 0 to 3 based on the presence and intensity of PD signal. Disease activity was determined by the presence of $\mathrm{SH} \geq 2$ degree and a positive PD signal.

Results: We found a persistent synovitis in 23 (35.9\%) of the PsA with clinical remission of the peripheral joint involvement. Active synovitis was also found in 7 